\title{
Muscle Glucose Metabolism following Exercise in the Rat
}

\author{
INCREASED SENSITIVITY TO INSULIN
}

\author{
Erik A. Richter, Lawrence P. Garetto, Michael N. Goodman, and \\ Neil B. Ruderman, Evans Memorial Department of Medicine, Division of \\ Diabetes and Metabolism, Boston University Medical Center, Boston, \\ Massachusetts 02118; Department of Medical Physiology B, Panum Institute, \\ University of Copenhagen, Denmark
}

A B S T R A C T Muscle glycogen stores are depleted during exercise and are rapidly repleted during the recovery period. To investigate the mechanism for this phenomenon, untrained male rats were run for $45 \mathrm{~min}$ on a motor-driven treadmill and the ability of their muscles to utilize glucose was then assessed during perfusion of their isolated hindquarters. Glucose utilization by the hindquarter was the same in exercised and control rats perfused in the absence of added insulin; however, when insulin $(30-40,000 \mu \mathrm{U} / \mathrm{ml})$ was added to the perfusate, glucose utilization was greater after exercise. Prior exercise lowered both, the concentration of insulin that half-maximally stimulated glucose utilization (exercise, $150 \mu \mathrm{U} / \mathrm{ml}$; control, 480 $\mu \mathrm{U} / \mathrm{ml}$ ) and modestly increased its maximum effect. The increase in insulin sensitivity persisted for $4 \mathrm{~h}$ following exercise, but was not present after $24 \mathrm{~h}$. The rate-limiting step in glucose utilization enhanced by prior exercise appeared to be glucose transport across the cell membrane, as in neither control nor exercised rats did free glucose accumulate in the muscle cell.

Following exercise, the ability of insulin to stimulate the release of lactate into the perfusate was unaltered; however its ability to stimulate the incorporation of $\left[{ }^{14} \mathrm{C}\right]$ glucose into glycogen in certain muscles was enhanced. Thus at a concentration of $75 \mu \mathrm{U} / \mathrm{ml}$ insulin stimulated glycogen synthesis eightfold more in the fast-twitch red fibers of the red gastrocnemius than it did in the same muscle of nonexercised rats. In contrast, insulin only minimally increased glycogen synthesis in the fast-twitch white fibers of the gastrocnemius, which were not glycogen-depleted. The uptake of 2-deoxyglucose by these muscles followed a similar pattern suggesting that glucose transport was also differentially enhanced. Prior exercise did not enhance

Received for publication 20 July 1981 and in revised form 28 October 1981. the ability of insulin to convert glycogen synthase from its glucose-6-phosphate-dependent (D) to its glucose6-phosphate-independent (1) form. On the other hand, following exercise, insulin prevented a marked decrease in muscle glucose-6-phosphate, which could have diminished synthase activity in situ. The possibility that exercise enhanced the ability of insulin to convert glycogen synthase $D$ to an intermediate form of the enzyme, more sensitive to glucose-6-phosphate, remains to be explored.

These results suggest that following exercise, glucose transport and glycogen synthesis in skeletal muscle are enhanced due at least in part to an increase in insulin sensitivity. They also suggest that this increase in insulin sensitivity occurs predominantly in muscle fibers that are deglycogenated during exercise.

\section{INTRODUCTION}

Muscle glycogen stores depleted during exercise are rapidly replenished during the recovery period (1-3). In keeping with this observation, Maehlum and his coworkers (2) have noted in man that the greatest proportion of a glucose load ingested following bicycle exercise is taken up by leg muscle rather than liver as in the resting state. The basis for this increase in glucose utilization by muscle is unknown. Wahren et al. (4) noted a modest increase in circulating insulin following exercise; however, it has been shown in the rat that muscle glycogen synthesis can occur rapidly during the recovery period, even when plasma insulin is not increased $(1,3)$. More recently, Ahlborg, Wahren and Felig (5) have observed a similar phenomenon in man.

In a preliminary study (6), we observed that the ability of insulin to stimulate glucose uptake by the incubated soleus muscle is increased when the muscle is taken from a rat following a 60 -min swim in tepid water. This proved to be an unsatisfactory model for 
further study, as the young rats $(50 \mathrm{~g})$ needed for these investigations frequently had a great deal of difficulty swimming, and the basal rates of glucose uptake by their incubated soleus muscles were variable. Also, effects of insulin at low concentrations are often difficult to demonstrate in the incubated rat soleus, and the maximum increments in glucose uptake induced by insulin are usually only approximately twofold (7). For this reason, we chose to assess the effect of prior exercise on insulin sensitivity in skeletal muscle using a different approach. Rats weighing $200 \mathrm{~g}$ were exercised by running on a treadmill and the response of their muscles to insulin following exercise was assessed in the isolated perfused rat hindquarter (8). Effects of insulin on this preparation are readily demonstrable at concentrations $<100 \mu \mathrm{U} / \mathrm{ml}$ and insulin-induced increases in glucose uptake may be as much as 10-fold (9). This report describes the effect of $45 \mathrm{~min}$ of moderate exercise on the subsequent response to insulin of glucose uptake, glycogen synthesis, and the activity ratio of glycogen synthase, i.e., synthase activity (minus glucose-6-phosphate)/synthase activity (plus glucose-6-phosphate at saturating concentrations). The results suggest that prior exercise enhances both the sensitivity of the glucose transport system to insulin and glycogen synthesis. They also suggest that these effects are most prominent in muscle fibers that are deglycogenated during the exercise. A preliminary report of this work has appeared (10).

\section{METHODS}

Animals. Male Sprague-Dawley rats were obtained from Charles River Breeding Laboratories (Wilmington, MA), and were fed Purina rat chow (Ralston Purina Co., St. Louis, MO) ad lib. To accustom them to treadmill running, all rats were run for $5 \mathrm{~min}$ at a rate of $18 \mathrm{~m} / \mathrm{min}$ on the 5 th, 4th, $3 \mathrm{rd}$, and 2 nd $\mathrm{d}$ before the experiment. On the morning of the experiment (when the rats weighed $200-250 \mathrm{~g}$ ), they were randomly divided into a resting and an exercising group. The exercising group ran for $\mathbf{4 5} \mathrm{min}$ on the treadmill at $18 \mathrm{~m} / \mathrm{min}$ except for the last $2 \mathrm{~min}$, during which the speed was increased to $31 \mathrm{~m} / \mathrm{min}$.

Perfusion studies. At various times after running on the treadmill, the exercised rats were anesthetized by an intraperitoneal injection of pentobarbital $(5 \mathrm{mg} / 100 \mathrm{~g}$ body $\mathrm{wt})$, as were resting controls. They were then surgically prepared for hindquarter perfusions as described previously (8). All rats had free access to food until they were anesthetized. The perfusion apparatus was similar to that described by Ruderman and his co-workers (8) as modified by Goodman et al. (11). To maintain the temperature of the perfusate more precisely at $37-38^{\circ} \mathrm{C}$, a heating coil was inserted in the system. The perfusion medium contained Krebs-Henseleit solution, rejuvenated aged human erythrocytes $(12,13)$ added to obtain a hematocrit of $30 \%, 4 \%$ bovine serum albumin (Pentex Corporation, Kankakee, IL), $6 \mathrm{mM}$ glucose, $0.15 \mathrm{mM}$ pyruvate, and $1.5-2 \mathrm{mM}$ lactate (originating from the erythrocytes). Porcine insulin (Lot No. PJ 5589), kindly provided by Dr. W. Shaw, Eli Lilly \& Co., Indianapolis, IN was present in concentrations ranging between 0 and 40,000 $\mu \mathrm{U} / \mathrm{ml}$ cell-free perfusate. The initial volume of perfusate was $150 \mathrm{ml}$. Immediately before placement in the perfusion apparatus, the rats were killed by an intracardiac injection of pentobarbital.

The hindquarter was initially perfused for $12 \mathrm{~min}$ to allow equilibration. The first $25 \mathrm{ml}$ of perfusate passed through the preparation was discarded, whereupon the medium was recirculated at a flow-rate of $12.5 \mathrm{ml} / \mathrm{min}$. When isotopes were added, $4 \mu \mathrm{Ci}$ of $\left[\mathrm{U}-{ }^{14} \mathrm{C}\right.$ ]glucose or $4 \mu \mathrm{Ci}$ of [carboxy${ }^{14} \mathrm{C}$ ]inulin (New England Nuclear, Boston, MA) were introduced into the reservoir $3 \mathrm{~min}$ before the end of the equilibration period. The transit time from the reservoir to the hindquarter was $\sim 2 \mathrm{~min}$ at the flow-rate used. After the equilibration period (at $0 \mathrm{~min}$ ) and in some experiments at 15 and $30 \mathrm{~min}$, samples were taken from the perfusate reservoir into 2 vol of $6 \%$ ice-cold $\mathrm{HClO}_{4}$ for lactate determination and into iced tubes for glucose determination. At $45 \mathrm{~min}$, samples of both perfusate and muscle were taken. The superficial part of the gastrocnemius muscle, consisting primarily of fast-twitch white fibers (14) was freeze-clamped in situ with aluminum clamps cooled in liquid nitrogen. After this, the soleus-gastrocnemius-plantaris muscle group was reflected, and the soleus muscle, which contains primarily slow-twitch red fibers $(14,15)$ was freeze clamped. Finally, a portion of the deep part of the medial head of the gastrocnemius muscle, which contains primarily fast-twitch red fibers (13) was excised and frozen. Muscles were stored under liquid nitrogen until analyzed.

To study the uptake of 2-deoxyglucose, $1 \mathrm{mM} \mathrm{2-[1,2-}$ ${ }^{3} \mathrm{H}$ ]deoxyglucose (New England Nuclear) was added to a glucose-free perfusate following the equilibration period. Uptake of label by individual muscles was determined in perchloric acid extracts and was corrected for counts in the extracellular space, the volume of which was determined using $\left[{ }^{14} \mathrm{C}\right]$ inulin. Tissue was taken after $30 \mathrm{~min}$ of perfusion, at which time the uptake of 2-deoxyglucose was still linear.

Analyses. Glucose in the perfusate was measured with a YS1 model 23A glucose analyzer (Yellow Springs Instruments Company, Inc., Yellow Springs, $\mathrm{OH}$ ). Perfusate lactate and muscle concentrations of glucose, glucose-6-phosphate, and fructose-6-phosphate were determined as previously described (16), as was the incorporation of labeled glucose into glycogen (17). For the calculation of net glycogen synthesis, the specific activity of glucose in the perfusate was determined in the 0 min sample. Glycogen was determined according to Karlsson et al. (18) and glycogen synthase as described by Thomas, Schlender, and Larner (19). Synthase activity measured with and without glucose-6-phosphate in the assay mixture will be referred to as "total (independent [I] plus dependent [D]) synthase activity" and "synthase I activity," respectively. The data are expressed as activity ratios, i.e., the ratio synthase activity (- glucose-6-phosphate)/synthase activity (+ glucose-6-phosphate in saturating concentration).

Calculations and statistics. Rates of glucose uptake and lactate release were determined from changes in their concentrations in the perfusate and are expressed per gram muscle perfused. The values were corrected for lactate production by erythrocytes. Glucose uptake by erythrocytes was not measurable. Previous studies have shown that the weight of the muscle perfused equals one-sixth of total body weight (8).

Glucose uptake was statistically analyzed by a two-by-five factorial analysis of variance and significant differences were located by the unpaired $t$ test. Significant differences in muscle glycogen concentrations were located by the unpaired $t$ test. The remaining data were analyzed by a twoby-two analysis of variance. 
TABLE I

Muscle and Liver Glycogen Immediately after Treadmill Exercise and during the Recovery Period

\begin{tabular}{|c|c|c|c|c|c|}
\hline \multirow[b]{2}{*}{ Tissue } & \multirow[b]{2}{*}{ Resting control } & \multicolumn{4}{|c|}{ Glycogen $(\mu \mathrm{mol} / \mathrm{g}$ wet wt) Time after exercise (h) } \\
\hline & & 0 & 1 & 2 & 4 \\
\hline Soleus & $26.7 \pm 1.2(5)$ & $13.3 \pm 1.6(5)^{\circ}$ & $23.0 \pm 2.1(3)$ & $31.9 \pm 1.8(3)^{\circ}$ & $38.9 \pm 1.4(2)$ \\
\hline Red gastrocnemius & $30.5 \pm 2.0(5)$ & $20.7 \pm 2.1(5)^{\circ}$ & $33.8 \pm 2.4(3)$ & $38.3 \pm 1.9(3)^{\circ}$ & $34.0 \pm 1.2(3)$ \\
\hline White gastrocnemius & $35.7 \pm 4.2(5)$ & $35.5 \pm 1.4(5)$ & $31.3 \pm 0.7(3)$ & $33.3 \pm 1.5(3)$ & $31.6 \pm 3.6(2)$ \\
\hline Liver & $176 \pm 18$ & $91 \pm 16(4)^{\circ}$ & & & \\
\hline
\end{tabular}

Rats were sacrificed either at rest or at various times after treadmill running. They were allowed free access to food and water both before running and during the recovery period. Results are means $\pm \mathrm{SE}$ with numbers of observations in parentheses.

- $P<0.05$ compared with resting controls.

\section{RESULTS}

Effect of treadmill running on muscle glycogen concentrations. Treadmill running resulted in substantial decreases in glycogen in the soleus muscle and the red component of the gastrocnemius, but not in the white gastrocnemius (Table I), indicating that exercise was of a moderate intensity (20). Liver glycogen was also diminished. The glycogen concentrations of both the soleus and the red gastrocnemius returned to normal within $l \mathrm{~h}$ of the cessation of exercise, and at $2 \mathrm{~h}$ they were significantly higher than in rats that had not exercised. Comparable increases in glycogen were not observed in the white gastrocnemius.

Glucose uptake in perfused hindquarter. To determine whether exercise altered the ability of insulin to stimulate glucose utilization, glucose uptake was compared in perfused hindquarters of exercised and nonexercised rats. The data presented in Table II indicate that glucose utilization was similar in the two groups in the absence of insulin, but that it was higher in the exercised group at concentrations of insulin between 30 and $40,000 \mu \mathrm{U} / \mathrm{ml}$. This was, in large part, due to an increase in insulin sensitivity (21). As illustrated in Fig. 1, in which glucose uptake is plotted as a percentage of the maximum insulin-stimulated value achieved, insulin exerted its half-maximal effect at 150 $\mu \mathrm{U} / \mathrm{ml}$ in the exercised group vs. $480 \mu \mathrm{U} / \mathrm{ml}$ in the controls. At a concentration of $75 \mu \mathrm{U} / \mathrm{ml}$, the stimulation of glucose uptake by insulin (after correcting for uptake in the absence of insulin) was threefold greater in the exercised than in the control group (Table II). The data also suggest that the maximum capacity for glucose uptake is increased following exercise, as glucose utilization was still somewhat higher in the exercised group in the presence of 20,000 and $40,000 \mu \mathrm{U} / \mathrm{ml}$ of insulin (Table II), concentrations that produce maximal effects in resting muscle (Table II) $(9,22)$.

Duration of increase in insulin sensitivity. To determine the duration of the increase in insulin sensi- tivity, hindquarters were perfused with $75 \mu \mathrm{U} / \mathrm{ml}$ of insulin 1, 2, and $4 \mathrm{~h}$ following exercise. As shown in Fig. 2, the increase in insulin sensitivity persisted for at least $4 \mathrm{~h}$, although at $4 \mathrm{~h}$ the absolute rate of glucose uptake was significantly less than at 0 hours. $24 \mathrm{~h}$ after exercise, the increase in insulin sensitivity was no longer present (data not shown). The increase in sensitivity to insulin persisted throughout the full $45 \mathrm{~min}$ of perfusion (Fig. 3), and in two experiments in which it was assessed, it was still evident at $2 \mathrm{~h}$. The relatively low rates of glucose uptake during the first $15 \mathrm{~min}$ of the perfusion (Fig. 3) are characteristic of the hindquarter preparation when physiological concentrations of insulin are used.

In four experiments the maximum reponsiveness of glucose utilization to insulin following exercise was

TABLE II

Glucose Utilization by the Isolated Perfused Hindquarter following Treadmill Running. Effect of Insulin

\begin{tabular}{rcc}
\hline & \multicolumn{2}{c}{ Glucose uptake } \\
\cline { 2 - 3 } Insulin & Control & Postexercise \\
\hline \multirow{2}{*}{$\mu U / \mathrm{ml}$} & \multicolumn{2}{c}{$\mu \mathrm{mol} / \mathrm{g} / \mathrm{h}$} \\
0 & $1.8 \pm 0.2(4)$ & $1.9 \pm 0.4(5)$ \\
10 & $2.2 \pm 0.3(8)$ & $2.8 \pm 0.2(8)$ \\
30 & $1.9 \pm 0.2(4)$ & $2.7 \pm 0.2(4)^{\circ}$ \\
75 & $3.2 \pm 0.2(12)$ & $6.1 \pm 0.3(13)^{\circ}$ \\
500 & $6.3 \pm 0.1(3)$ & $9.4 \pm 1.1(3)^{\circ}$ \\
20,000 & $10.2 \pm 0.9(8)$ & $12.6 \pm 0.5(8)^{\circ}$ \\
40,000 & $10.6 \pm 0.2(3)$ & $12.1 \pm 0.2(2)^{\circ}$ \\
\hline
\end{tabular}

Hindquarters were placed in the perfusion system $\sim 20 \mathrm{~min}$ after the cessation of exercise or an equivalent period of rest. After 12 min of equilibration, glucose utilization was measured over the next $45 \mathrm{~min}$. Control rats were not exercised. Insulin at the indicated concentrations was added to the initial cell-free perfusate. Between 10 and $20 \%$ of the insulin was degraded during the perfusion. Results are means $\pm \mathrm{SE}$ with numbers of observations in parentheses. - $P<0.05$ when compared with control values. 


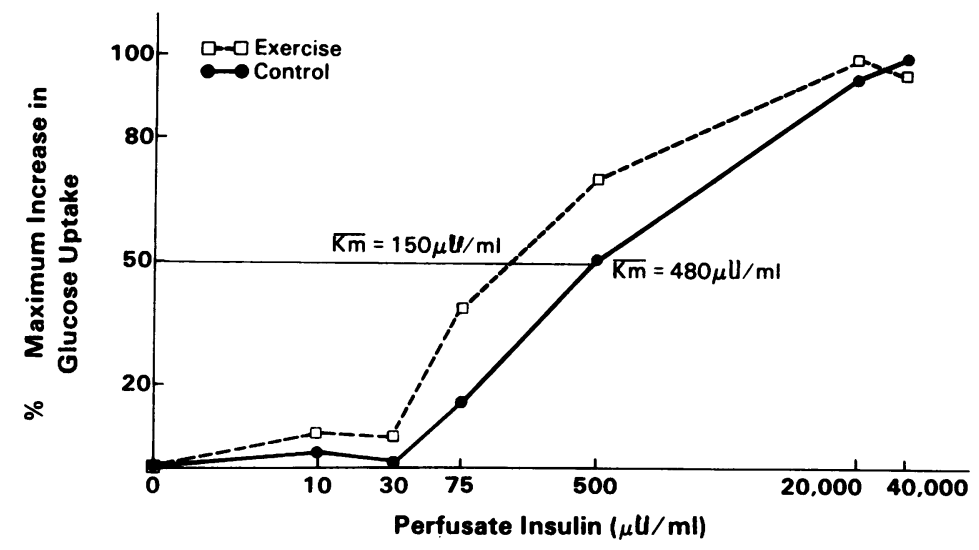

Figure 1 Dose response of glucose uptake following exercise. Effect of prior exercise on stimulation of glucose utilization by insulin in the perfused hindquarter. Results are expressed as a percentage of maximum insulin effect. See Table II legend and Methods for details.

found to be increased only in the first 15 min of a 45 min perfusion (data not shown). The significance of this observation remains to be determined.

Glucose disposition in perfused hindquarter. The major fates of glucose taken up by the rat hindquarter are conversion to glycogen and release as lactate; smaller amounts are released as pyruvate and alanine or are oxidized $(23,24)$. The release of lactate by hindquarters from control and exercised rats in this study was low and there were no differences between the groups (data not shown). On the other hand, the in-

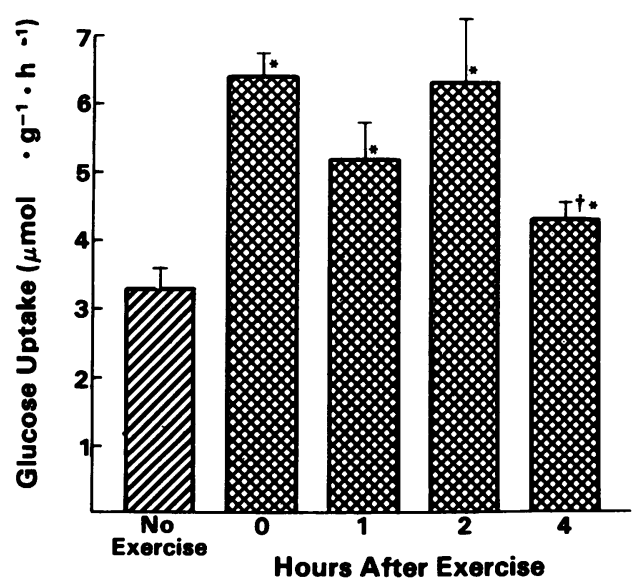

Figure 2 Duration of increase in insulin sensitivity following exercise (insulin, $75 \mu \mathrm{U} / \mathrm{ml}$ ). Stimulation of glucose uptake by insulin in rat hindquarters perfused at different times following exercise. The perfusate contained insulin at a concentration of $75 \mu \mathrm{U} / \mathrm{ml}$ cell-free perfusate. Results are means $\pm \mathrm{SE}$ with numbers of observations in parentheses. See Table II legend for details.

- $P<0.05$ when compared with rested control group. t $P<0.05$ when compared with 0 min group. corporation of $\left[\mathrm{U}-{ }^{14} \mathrm{C}\right]$ glucose into glycogen was greater following exercise (Table III). This was most evident in the presence of insulin, although a trend to increased glycogen synthesis was seen when insulin was not added. The greatest stimulation of glucose incorporation into glycogen by insulin following exercise was seen in the red gastrocnemius, a muscle partially depleted of glycogen by the run, and the smallest increase in the white gastrocnemius, which was not depleted of glycogen. The response of the soleus, which was also partially depleted of glycogen, was intermediate.

Glycogen synthase. Enzyme activity was measured in muscles taken at the end of a 45-min perfusion. Glucose utilization in the presence of insulin was still enhanced by prior exercise at this time (Fig. 2), as was, presumably, glucose incorporation into glycogen. Thus, it was of special interest to determine if the activity ratio of glycogen synthase was also increased, as it is widely held that only the glucose-6-phosphate-independent form is active in vivo (25). As shown in Table IV, prior exercise by itself increased the activity ratio only in the soleus. It caused but a small increase in the ability of insulin $(75 \mu \mathrm{U} / \mathrm{ml})$ to increase the activity ratio in the red gastrocnemius and it had no effect in the white gastrocnemius. In the soleus, insulin increased the activity ratio by itself; however the increase was the same whether or not the rat had previously exercised. It remains to be determined if insulin had a greater effect on the activity ratio in the exercised group earlier in the perfusion.

Tissue glucose and 2-deoxyglucose uptake. After correcting for glucose in the extracellular space, free glucose was not detectable intracellularly in any of the groups studied (Table V). Thus, transport into the muscle cell appeared to be the rate-limiting, insulin- 


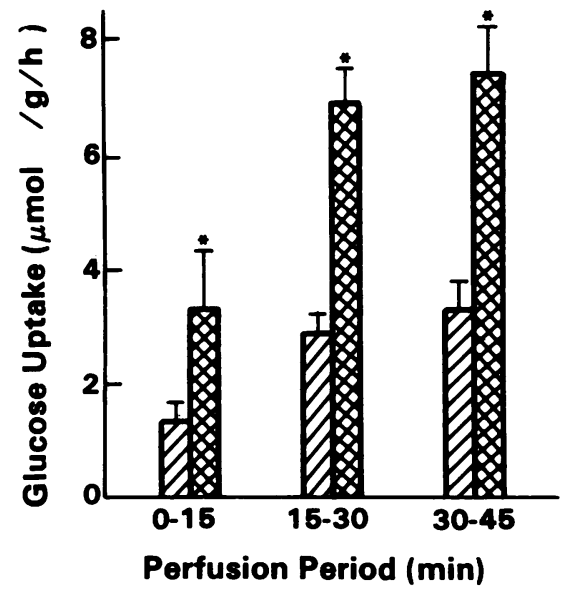

Figure 3 Time-course of glucose uptake in perfused hindquarters from rested and previously exercised rats. Glucose uptake was determined during three successive $15-\mathrm{min}$ periods following $12 \mathrm{~min}$ of equilibration. The perfusate contained insulin at a concentration of $75 \mu \mathrm{U} / \mathrm{ml}$ cell-free perfusate. Values are means $\pm S E$ of four observations. See Table II legend for details.

sensitive step enhanced by prior exercise that resulted in increased glucose utilization. In accord with this notion, when hindquarters were perfused with 2-deoxyglucose to assess hexose transport, the stimulation of its uptake into the red gastrocnemius by insulin (75 $\mu \mathrm{U} / \mathrm{ml}$ ) was increased fourfold by prior exercise from $0.4 \pm 0.1($ mean $\pm \mathrm{SE}, n=3)$ to $1.6 \pm 0.4(n=4) \mu \mathrm{mol} /$ $g$ per $h$. In keeping with its effect on glycogen synthesis, exercise did not enhance the stimulation of 2 deoxyglucose uptake into the white gastrocnemius (control $0.4 \pm 0.1 \quad(n=3)$; exercise $0.6 \pm 0.25 \quad(n=4)$ $\mu \mathrm{mol} / \mathrm{g}$ per $\mathrm{h}$ ). Interestingly, we also found no increase in 2-deoxyglucose uptake by the soleus (control $0.9 \pm 0.2$ $(n=3)$; exercise $0.7 \pm 0.2(n=4) \mu \mathrm{mol} / \mathrm{g}$ per h).

Hexose phosphates. Glucose-6-phosphate and fructose-6-phosphate were measured in the soleus and white gastrocnemius. They were not determined in the red gastrocnemius, since this muscle had to be excised before it could be freeze-clamped and this results in rapid increases in hexose phosphate concentration. As shown in Table VI, when perfused without insulin added to the medium, the concentrations of both, glucose-6-phosphate and fructose-6-phosphate were decreased in the soleus and, to a lesser extent, in the white gastrocnemius of previously exercised rats. The addition of insulin to the perfusate caused a two- to threefold increase in the concentrations of both hexose phosphates in the soleus, but it did not produce a significant increase in their concentrations in the white gastrocnemius.

\section{DISCUSSION}

Muscle glycogen is a major fuel for working muscle during exercise $(26,27)$. At the time they were perfused, the soleus and gastrocnemius almost certainly had largely repleted their glycogen stores (Table I). Furthermore, as shown by Bergstrom and his colleagues (28), when its glycogen stores are depleted during exercise, a muscle loses its capacity for heavy work and exhaustion ensues. For these reasons, the maintenance of muscle glycogen is of special importance to mobile organisms and its repletion following exercise is of high priority metabolically.

The results of the present study indicate that the ability of the rat to resynthesize its muscle glycogen stores following exercise is in part due to an increase in insulin sensitivity. Thus, after $45 \mathrm{~min}$ of low-inten-

TABLE III

Effect of Prior Exercise and of Insulin on Glucose Incorporation into Glycogen by the Isolated Perfused Rat Hindquarter

\begin{tabular}{lccc}
\hline & \multicolumn{3}{c}{ Glucose incorporation into glycogen } \\
\cline { 2 - 4 } & Soleus & $\begin{array}{c}\text { Red } \\
\text { gastrocnemius }\end{array}$ & $\begin{array}{c}\text { White } \\
\text { gastrocnemius }\end{array}$ \\
& & $\mu m o l / g / h$ & \\
No insulin & & & \\
$\quad$ Control & & & $0.06 \pm 0.01$ \\
Postexercise & $0.17 \pm 0.02$ & $0.10 \pm 0.02$ & $0.10 \pm 0.04$ \\
Insulin $(75 \mu \mathrm{U} / \mathrm{ml})$ & $0.43 \pm 0.14$ & 0.12 & \\
$\quad$ Control & & & $0.18 \pm 0.03$ \\
Postexercise & $0.79 \pm 0.25$ & $3.08 \pm 0.64^{\circ}$ & $0.37 \pm 0.07^{\circ}$ \\
\hline
\end{tabular}

Results are means \pm SE of 9-10 observations when insulin was present and 4-5 observations when insulin was not added. See legend to Table II for details.

- $P<0.05$ when compared with control values. 
TABLE IV

Effect of Prior Exercise and of Insulin on Glycogen Synthase Activity in Muscles of Isolated Perfused Rat Hindquarter

\begin{tabular}{|c|c|c|c|}
\hline & \multicolumn{3}{|c|}{ Glycogen synthase (activity ratio) } \\
\hline & Soleus & Red gastrocnemius & $\begin{array}{c}\text { White } \\
\text { gastrocnemius }\end{array}$ \\
\hline \multicolumn{4}{|l|}{ No insulin } \\
\hline Control & $0.09 \pm 0.02(4)$ & $0.17(2)$ & $0.24 \pm 0.07$ \\
\hline Postexercise & $0.20 \pm 0.01(4)^{\circ}$ & $0.17 \pm 0.01$ & $0.29 \pm 0.06(4)$ \\
\hline \multicolumn{4}{|c|}{ Insulin $(75 \mu \mathrm{U} / \mathrm{ml})$} \\
\hline Control & $0.16 \pm 0.02(7) \ddagger$ & $0.17 \pm 0.01(7)$ & $0.26 \pm 0.03(8)$ \\
\hline Postexercise & $0.26 \pm 0.03(7)^{\bullet}$ & $\left.0.21 \pm 0.01(8)^{\circ}\right\rfloor$ & $0.27 \pm 0.02(7)$ \\
\hline
\end{tabular}

Total synthase (glucose-6-phosphate independent [I] plus dependent [D] activities were $1.87 \pm 0.19,1.67 \pm 0.26$ and $1.36 \pm 0.25$ (mean $\pm \mathrm{SE}, n=8) \mu \mathrm{mol} / \mathrm{min}$ per $\mathrm{g}$ muscle in the soleus and red and white gastrocnemius, respectively, after $45 \mathrm{~min}$ of perfusion of control hindquarters with $75 \mu \mathrm{U} / \mathrm{ml}$ of insulin in the cell-free perfusate. Total activity was not different in rats that had previously exercised. Results are means $\pm S E$ with numbers of observations in parentheses.

- $P<0.05$ when compared with corresponding control values.

$\ddagger P<0.05$ when compared with corresponding values in the absence of insulin.

sity running on a treadmill, the concentration of insulin needed to produce a half-maximal increase in glucose utilization was $150 \mu \mathrm{U} / \mathrm{ml}$ vs. $480 \mu \mathrm{U} / \mathrm{ml}$ in a group of nonexercised controls (Fig. 1). At an insulin concentration of $75 \mu \mathrm{U} / \mathrm{ml}$, the stimulation of glucose utilization was threefold greater in the exercised group (Table II). An increase in the maximum rate of glucose utilization in response to insulin was also noted following exercise; however, it was modest and only persisted for the first $15 \mathrm{~min}$ of a 45 -min perfusion. Glucose utilization was not increased following exercise in the absence of insulin, indicating that prior glycogen de- pletion by itself was not a sufficient stimulus to enhance glucose uptake.

A similar increase in insulin sensitivity has been observed in rat (7) and mouse (29) soleus muscles after $48 \mathrm{~h}$ of starvation. In both instances insulin binding was increased due to an enhanced affinity of membrane receptors for insulin or an increase in the number of a subclass of high-affinity binding sites. The total number of insulin receptors was either unchanged or minimally increased. Pederson and his colleagues (30) and Koivisto et al. (31) have reported that insulin binding to monocytes $(30,31)$ and erythrocytes $(31)$

TABLE V

Effect of Prior Exercise and Insulin on the Free Glucose Concentration in Muscles of the Isolated Perfused Hindquarter

\begin{tabular}{|c|c|c|c|}
\hline & \multicolumn{3}{|c|}{ Glucose in cell $\mathrm{H}_{2} \mathrm{O}$} \\
\hline & Soleus & Red gastrocnemius & $\begin{array}{c}\text { White } \\
\text { gastrocnemius }\end{array}$ \\
\hline & \multicolumn{3}{|c|}{$\mu \mathrm{mol} / \mathrm{ml}$} \\
\hline \multicolumn{4}{|l|}{ No insulin } \\
\hline Control & $0.2 \pm 0.1$ & $-0.3 \pm 0.03(4)$ & $-0.2 \pm 0.05(4)$ \\
\hline Exercise & $-0.4 \pm 0.2$ & $-0.4 \pm 0.1$ & $0 \pm 0.1$ \\
\hline \multicolumn{4}{|c|}{ Insulin $(75 \mu \mathrm{U} / \mathrm{ml})$} \\
\hline Control & $0.1 \pm 0.1$ & $-0.2 \pm 0.1$ & $-0.1 \pm 0.05$ \\
\hline Exercise & $-0.1 \pm 0.06$ & $-0.1 \pm 0.4$ & $-0.1 \pm 0.05$ \\
\hline
\end{tabular}

Results are means $\pm \mathrm{SE}$ with numbers of observations in parentheses. Cell glucose was calculated as described by Berger et al. (22). Glucose concentration in the perfusate at the time of muscle sampling was $\sim 5 \mathrm{mM}$ (Methods). 
TABLE VI

Effect of Prior Exercise and of Insulin on the Concentrations of Glucose-6Phosphate and Fructose-6-Phosphate in Muscles of the Isolated Perfused Rat Hindquarter

\begin{tabular}{llllll}
\hline & \multicolumn{2}{c}{ Soleus } & & \multicolumn{2}{c}{ White gastrocnemius } \\
\cline { 2 - 3 } \cline { 5 - 6 } & G-6-P & F-6-P & & G-6-P & F-6-P \\
\hline & & $n m o l / g$ & & & \multicolumn{2}{c}{$n m o d / g$} \\
No insulin & & & & & \\
$\quad$ Control (4) & $248 \pm 21$ & $55 \pm 5$ & & $214 \pm 51$ & $40 \pm 8$ \\
$\quad$ Postexercise (4) & $134 \pm 44^{\circ}$ & $26 \pm 10^{\circ}$ & & $128 \pm 27$ & $29 \pm 7$ \\
Insulin (75 $\mu \mathrm{U} / \mathrm{ml})$ & & & & & \\
$\quad$ Control (6) & $324 \pm 26 !$ & $61 \pm 5$ & & $265 \pm 45$ & $39 \pm 7$ \\
Postexercise (7) & $343 \pm 42 !$ & $70 \pm 28$ & & $188 \pm 28$ & $36 \pm 4$ \\
\hline
\end{tabular}

Results are means $\pm \mathrm{SE}$ with numbers of observations in parentheses. See legend to Table III and Methods for details. G-6-P, glucose-6-phosphate; F-6-P, fructose-6-phosphate.

- $P<0.05$ when compared with corresponding control values.

$f P<0.05$ when compared with corresponding value in absence of insulin.

is increased in man following exercise, due to an apparent increase in receptor affinity. The relevance of these findings to muscle is uncertain however, for as shown in this study, the increased ability of insulin to stimulate glucose utilization and glycogen synthesis following exercise appears to be restricted to muscles that had been deglycogenated. Thus, if alterations in insulin binding account for the observed findings local rather than systemic factors would have to be implicated.

As shown previously $(9,22)$, except during exercise itself, free glucose does not usually accumulate in skeletal muscle, indicating that transport is the rate-limiting step in glucose utilization. Free glucose was not detectable in the muscle cell in the present study, either at rest or following exercise, and it did not accumulate when insulin was added to the perfusate. This suggests that transport was also rate-limiting in these situations and that following exercise the enhanced ability of insulin to stimulate glucose utilization was exerted at least in part at this step. The finding that prior exercise enhanced the ability of insulin to stimulate the uptake of 2-deoxyglucose by the red gastrocnemius supports this conclusion as does the observation that insulin increased intracellular glucose-6phosphate in the soleus following exercise. The concentration of the latter should have been decreased if the primary effect of insulin was on glycogen synthesis.

The principal fates of glucose taken up by perfused rat skeletal muscle are conversion to glycogen and release as lactate $(23,24)$. Prior exercise enhanced the ability of insulin to stimulate glucose incorporation into glycogen, but it had no effect on the release of lactate. This suggests that, in addition to stimulating glucose transport into the muscle cell, exercise specifically enhanced the ability of insulin to stimulate glycogen synthesis. In the red gastrocnemius, this increase in glycogen synthesis was associated with only a small increase in the activity ratio of glycogen synthase. In the soleus the activity ratio was considerably increased by both prior exercise and by insulin; however, the insulin-induced increase was the same in exercised and nonexercised muscle. Thus, except perhaps in the soleus, it is unlikely that an increase in the fraction of synthase in its glucose-6-phosphate independent (I) form contributed to the increased stimulation of glycogen synthesis by insulin following exercise.

Glycogen synthase activity may have been increased following exercise by other mechanisms. By stimulating glucose transport, insulin increased the concentration of glucose-6-phosphate in the soleus following exercise from 134 to $343 \mathrm{nmol} / \mathrm{g}$. As recently shown by Chiasson et al. (32), the concentration of glucose6-phosphate that causes a half-maximal activation of glycogen synthase $\left(\mathrm{A}_{0.5}\right)$ in posterior thigh muscle of the rat hindquarter is $370 \mu \mathrm{M}$. Thus, the higher glucose-6-phosphate concentration in muscle perfused with insulin following exercise might have enhanced synthase activity in situ. The relevance of this observation to the high rate of glycogen synthesis in vivo following exercise is debatable, however, as the concentrations of glucose-6-phosphate in muscle during the recovery period and at rest in intact organisms are very similar (33). More relevant may be the finding of Chiasson and his colleagues (32) that insulin at a concentration of $1,000 \mu \mathrm{U} / \mathrm{ml}$ lowers the $A_{0.5}$ of muscle glycogen synthase for glucose-6-phosphate in the hindquarter from 370 to $250 \mu \mathrm{M}$. Whether following ex- 
ercise lower concentrations of insulin can produce a similar change remains to be determined. That this may occur is suggested by the observation of Kochan and his colleagues $(34,35)$ that prior exercise diminishes the concentration of glucose-6-phosphate needed to produce a partial activation of glycogen synthase in both human and rat muscle for several hours following exercise. They suggested that, this as well as alterations in the sensitivity of glycogen synthase to other effectors, may be related to the appearance of an intermediate form of the enzyme with a different phosphorylation state (36). Of particular interest was their finding that such alterations in synthase activity (which in general paralleled changes in the $A_{0.5}$ ) persisted far longer than the increase in the activity ratio following exercise and that they correlated more closely with the synthesis of muscle glycogen during the period of supercompensation.

In the present study, the increase in insulin sensitivity of rat muscle following exercise lasted at least $4 \mathrm{~h}$, whereas in the intact rat glycogen stores had essentially been repleted by $1 \mathrm{~h}$ (Table I). Thus, the more prolonged increase in insulin sensitivity cannot be attributed to glycogen depletion per se and its cause remains to be determined. Temporally, it appears to be related to the period of increased sensitivity of glycogen synthase to glucose-6-phosphate $(34,35)$, as well as to the phenomenon of supercompensation, by which muscle increases its glycogen stores to higher than resting levels during the recovery period following exercise $(1,2,33)$. In addition to supercompensation, the increase in insulin sensitivity may explain, or partially explain, why glucose tolerance in man is often increased for many hours following exercise despite a normal or even a diminished insulin response (37). Also, it may explain why some insulin-requiring diabetics develop hypoglycemia (38) many hours following the cessation of exercise and why others experience a decrease in their requirement for insulin (39).

The exercise used in the present study was of moderate intensity for the rat as judged by the finding that only red muscles were depleted of glycogen (20). Whether more intense exercise leading to a depletion of glycogen in white muscle would result in an increase in insulin sensitivity in these fibers is not known. Likewise, it remains to be determined whether exercise alters the sensitivity to insulin of organs such as liver and adipose tissue, which may also be depleted of their fuel reservoirs during exercise, and whether it affects other insulin-sensitive processes such as amino acid transport and protein synthesis. Finally, as the ability of insulin to stimulate both glucose transport and glycogen synthase were enhanced by prior exercise, it is likely that an early event in insulin action, e.g., its binding to membrane receptors, was altered. This too, however, remains to be proven.

Note added in proof. While this manuscript was in press, Ivy and Holloszy (1981. Am. J. Physiol. 241: C200-C203) reported that glucose utilization by the perfused rat hindquarter is enhanced following $45 \mathrm{~min}$ of swimming even when insulin is not added to the perfusate. In addition to the type of exercise the rats in this study differed from those studied by us in that they were starved and their muscle glycogen had not been substantially repleted at the time of perfusion. Whether one or a combination of these factors account for the differing results remains to be determined.

\section{ACKNOWLEDGMENTS}

The authors are indebted to Ms. Mary Tortora and Ms. Glenda Cresto for typing the manuscript and Mrs. Eva Belur and Ms. Susan Dluz for their skilled technical assistance.

The present study was supported by U. S. Public Health Service grants AM19514, AM19469, and T32-AM07201, and by grants from the P. Carl Petersens Foundation (B 1120 and $B$ 1157).

\section{REFERENCES}

1. Conlee, R. K., R. C. Hickson, W. W. Winder, J. M. Hagberg, and J. O. Holloszy. 1978. Regulation of glycogen resynthesis in muscles of rats following exercise. Am. J. Physiol. 235: R145-R150.

2. Maehlum, S., P. Felig, and J. Wahren. 1978. Splanchnic glucose and muscle glycogen metabolism after glucose feeding during post-exercise recovery. Am. J. Physiol. 235: E255-E260.

3. Fell, R. D., J. A. McLane, W. W. Winder, and J. O. Holloszy. 1980. Preferential resynthesis of muscle glycogen in fasting rats after exhaustive exercise. Am. J. Physiol. 238: R328-R332.

4. Wahren, J., P. Felig, R. Hendler, and G. Ahlborg. 1973. Glucose and amino acid metabolism during recovery after exercise. J. Appl. Physiol. 34: 838-845.

5. Ahlborg, G., and Felig, P. 1982. Lactate and glucose exchange across the forearm, legs, and splanchnic bed during and after prolonged exercise. J. Clin. Invest. In press.

6. Ruderman, N. B., L. Brady, F. Kalish, and M. N. Goodman. 1980. Alterations in muscle metabolism in the diabetic rat. In Diabetes 1979 . W. K. Waldhausl, editor. International Congress Series 500. Excerpta Medica, Amsterdam-Oxford-Princeton. 329-332.

7. Brady, L. B., M. N. Goodman, F. R. Kalish, and N. B. Ruderman. 1981. Insulin binding and sensitivity in rat skeletal muscle: effect of starvation. Am. J. Physiol. 240: E184-E190.

8. Ruderman, N. B., C. R. S. Houghton, and R. Hems. 1971. Evaluation of the isolated perfused rat hindquarter for the study of muscle metabolism. Biochem. J. 124: 639651.

9. Goodman, M. N., and N. B. Ruderman. 1979. Insulin sensitivity of rat skeletal muscle: effects of starvation and aging. Am. J. Physiol. 265: E519-E523.

10. Garetto, L. P., E. A. Richter, and N. B. Ruderman. 1981. Increased insulin sensitivity of skeletal muscle following exercise. Diabetes. 30(Suppl. 1): 63a.

11. Goodman, M. N., T. T. Aoki, and N. B. Ruderman. 1978 
Metabolic effects of dichloroacetate in skeletal muscle. Diabetes. 27: 1065-1074.

12. Rennie, M. J., and J. O. Holloszy. 1977. Inhibition of glucose uptake and glycogenolysis by availability of oleate in well-oxygenated perfused skeletal muscle. Biochem. J. 168: 161-170.

13. Ruderman, N. B., F. W. Kemmer, M. N. Goodman, and M. Berger. 1980. Oxygen consumption in perfused skeletal muscle. Effect of perfusion with aged-fresh and aged-rejuvenated erythrocytes on oxygen consumption, tissue metabolites, and inhibition of glucose utilization by acetoacetate. Biochem. J. 190: 57-64.

14. Hickson, R. C., W. W. Heusner, W. D. Van Huss, J. F. Taylor, and R. E. Carrow. 1976. Effects of an anabolic steroid and sprint training on selected histochemical and morphological observations in rat skeletal muscle types. Eur. J. Appl. Physiol. Occup. Physiol. (Berlin). 35: 251259.

15. Ariano, M. A., R. B. Armstrong, and V. R. Edgerton. 1973. Hindlimb muscle fiber populations of five mammals. J. Histochem. Cytochem. 21: 51-55.

16. Goodman, M. N., M. Berger, and N. B. Ruderman. 1974. Glucose metabolism in rat skeletal muscle at rest. Effects of starvation, diabetes, ketone bodies, and free fatty acids. Diabetes. 23: 881-888.

17. Maizels, E. Z., N. B. Ruderman, M. N. Goodman, and D. Lau. 1977. Effect of acetoacetate on glucose metabolism in the soleus and extensor digitorum longus muscles of the rat. Biochem. J. 162: 557-568.

18. Karlsson, J., B. Diamant, and B. Saltin. 1971. Muscle metabolites during submaximal and maximal exercise in man. Scand. J. Clin. Lab. Invest. 26: 385-394.

19. Thomas, J. A., K. K. Schlender, and J. Larner. 1968. A rapid filter paper assay for UDP glucose-glycogen glucosyl-transferase, including an improved biosynthesis of UDP-14C-glucose. Anal. Biochem. 25: 486-499.

20. Armstrong, R. B., C. W. Saubert IV, W. L. Sembrowich, R. E. Shepheard, and P. D. Gollnick. 1974. Glycogen depletion in rat skeletal muscle fibers at different intensities and duration of exercise. Pfluegers Arch. 352: 243256.

21. Kahn, C. R. 1978. Insulin resistance, insulin insensitivity, and insulin unresponsiveness: a necessary distinction. Metab. Clin. Exp. 27: 1893-1902.

22. Berger, M., S. Hagg, and N. B. Ruderman. 1975. Glucose metabolism in perfused skeletal muscle. Interaction of insulin and exercise on glucose uptake. Biochem. J. 146: 231-238.

23. Berger, M., S. A. Hagg, M. N. Goodman, and N. B. Ruderman. 1976. Glucose metabolism in perfused skeletal muscle. Effects of starvation, diabetes, fatty acids, acetoacetate, insulin, and exercise on glucose uptake and disposition. Biochem. J. 158: 191-202.
24. Ruderman, N. B., M. N. Goodman, M. Berger, and S. Hagg. 1977. Effect of starvation on muscle glucose metabolism: studies with the isolated perfused rat hindquarter. Fed. Proc. 36: 171-176.

25. Piras, R., and R. Stanelloni. 1969. In vivo regulation of rat muscle glycogen synthase activity. Biochemistry. 8: 2153-2160.

26. Hermansen, L., E. Hultman, and B. Saltin. 1967. Muscle glycogen during prolonged severe exercise. Acta Physiol. Scand. 71: 129-139.

27. Pernow, B., and B. Saltin. 1971. Availability of substrates and capacity for prolonged heavy exercise in man. $J$. Appl. Physiol. 31: 416-422.

28. Bergstrom, J., L. Hermansen, E. Hultman, and B. Saltin. 1967. Diet, muscle, glycogen, and physical performance. Acta Physiol. Scand. 71: 140-150.

29. LeMarchand-Brustel, Y., and P. Freychet. 1979. Effect of fasting and streptozotozin diabetes on insulin binding and action in the isolated mouse soleus muscle. J. Clin. Invest. 64: 1505-1515.

30. Pedersen, O., H. Beck-Nielsen, and L. Heding. 1980. Increased insulin receptors after exercise in patients with insulin-dependent diabetes mellitus. N. Engl. J. Med. 302: 886-892.

31. Koivisto, V. A., V. R. Soman, and P. Felig. 1980. Effects of acute exercise on insulin binding to monocytes in obesity. Metab. Clin. Exp. 29: 168-172.

32. Chiasson, J. L., M. R. Dietz, H. Shikama, M. Wootten, and J. H. Exton. 1980. Insulin regulation of skeletal muscle glycogen metabolism. Am. J. Physiol. 239: E69E74.

33. Hultman, E., J. Bergstrom, and A. E. Roch-Norlund. 1971. Glycogen storage in human skeletal muscle. Adv. Exp. Med. Biol. 11: 273-288.

34. Kochan, R. G., D. R. Lamb, S. A. Lutz, C. V. Perrill, E. Reimann, and K. K. Schlender. 1979. Glycogen synthase activation in human skeletal muscle: effects of diet and exercise. Am. J. Physiol. 236: E660-E666.

35. Kochan, R. G., D. Lamb, E. Reimann, and K. K. Schlender. 1981. Modified assays to detect activation of glycogen synthase following exercise. Am. J. Physiol. 240: E197-E202.

36. Roach, P. J., and J. Larner. 1977. Covalent phosphorylation in the regulation of glycogen synthase activity. Mol. Cell. Biochem. 15: 179-200.

37. Pruett, E. D., and S. Oseid. 1970. Effect of exercise on glucose and insulin response to glucose infusion. Scand. J. Clin. Lab. Invest. 26: 277-285.

38. Richter, E. A., N. B. Ruderman, and S. H. Schneider. 1981. Diabetes and exercise. Am. J. Med. 70: 201-209.

39. Costill, D. L., P. Cleary, W. J. Fink, C. Foster, J. L. Ivy, and F. Witzmann. 1979. Training adaptations in skeletal muscle of juvenile diabetics. Diabetes. 28: 818-822. 